\title{
Optimization of Rapid Microwave Processing of Botanical Samples for Transmission Electron Microscopy
}

\author{
Joseph Mowery $^{1}$ and Gary Bauchan ${ }^{1}$
}

1. Electron and Confocal Microscopy Unit, United States Department of Agriculture, Agricultural Research Service, Beltsville, MD 20705, USA

Processing biological samples for transmission electron microscopy (TEM) using conventional processing methods are hindered by the slow rate of diffusion of reagents into the tissue, resulting in procedures typically taking 3-4 days to complete. Microwave (MW) irradiation drastically speeds up the rate of diffusion allowing the entire process to be completed within a few hours [1]. However, modern MW systems have improved considerably in recent years creating a need for revised protocols, especially for plant specimens which typically require additional processing steps [2]. In this study, we present a new optimized rapid MW protocol for preparing plant samples for TEM, utilizing the Pelco BioWave Pro+ MW system, examining leaf tissue from tobacco (Nicotiana tabacum) and tomato (Solanum lycopersicum).

During MW processing it is particularly critical that the leaf tissue is as small as possible and consistent among all samples [3]. Tissue is excised from the leaf using a $1 \mathrm{~mm}$ biopsy punch, ensuring consistent sample size and uniform radial diffusion of reagents into the tissue. The leaf tissue is fixed in $2 \%$ paraformaldehyde $2.5 \%$ glutaraldehyde, $0.2 \%$ Tween-20, $0.5 \mathrm{M}$ NaCacodylate and processed for TEM following the MW procedure listed in Table 1. A challenge specifically associated with plant leaf tissue is the high proportion of air in the intercellular space of the mesophyll, which typically causes leaf tissue to float on the surface of the fixative [4]. Air is remove from the leaf by the application of 5-15 vacuum breaks consisting of a 2 min vacuum at $20 \mathrm{inHg}$ followed by $2 \mathrm{~min}$ of venting. The addition of $0.2 \%$ Tween-20 to the fixative reduces surface tension on the surface of the leaf and dislodges air bubbles trapped by the trichomes (leaf hairs), further facilitating the tissue to sink into the fixative.

Plant leaves frequently possess a waxy cuticle which prevents the proper adhesion of resin, causing tissue to separate from the resin during sectioning. The addition of Z-6040 silane primer (3glycidoxypropyltrimethox-silane) during the dehydration process acts as a coupling agent enhancing the adhesion of the resin to the cuticle [5]. To our knowledge this is the first application using Z-6040 primer with plant tissue and epoxy resin. After resin infiltration, leaf tissue is placed in beem capsules, sealed with parafilm and polymerized in a two-step MW process underwater [1]. Ultrathin 70nm sections were cut using a Reichert/AO Ultracut ultramicrotome with a Diatome diamond knife, mounted onto 100 mesh carbon-formvar coated cooper grids, stained for 5 minutes with 3\% Reynolds lead citrate, and imaged at $80 \mathrm{kV}$ on a Hitachi HT7700 TEM.

Utilizing these methods, we not only significantly reduced the processing times, but also observed slight improvements in the preservation of the ultrastructural morphology of various organelles in tomato and tobacco leaves compared to conventional processing (Figure 1). We also observed morphology enhancements using MW polymerization compared to conventional oven polymerization. In some cases, small improvements may still be possible to reduce the time of this MW procedure even further. More work is needed to fully compare all the ultrastructural variations between conventional and MW processing across a wide range of plant tissue [6]. 
References:

[1] R. Giberson and R. Demaree. Methods in Molecular Biology, Vol 117: Electron Microscopy methods and protocols. ed. N. Hajibagheri. (Humana Press Inc., Totowa) p. 145-158.

[2] B. Zechmann and G Zellnig. Journal of Microscopy 233 (2009) p. 258-268

[3] K. McDonald. Microscopy and Microanalysis 20 (2014) p. 152-163.

[4] W. Russin and C Trivett. Microwave Techniques and Protocols. eds. R Giberson and R Demaree. (Humana Press Inc., Totowa) p. 25-35.

[5] M. Houck and V. Lindle. American Entomologist 39 (1993) p. 117-119.

[6] Mention of trade names or commercial products in this publication is solely for the purpose of providing specific information and does not imply recommendation or endorsement by the U.S.

Department of Agriculture. USDA is an equal opportunity provider and employer.

\begin{tabular}{|c|c|c|c|c|}
\hline Step & Time & Watts & Vacuum & Temperature \\
\hline Fixative / Vacuum (x5-10) & 2 Min Vacuum, 2 Min Vent (x5-10) & 0 & On & $60^{\circ} \mathrm{C}$ \\
\hline Primary Fixative & 2 Min On, 2 Min Off, 2 Min On & 150 & Cycle $^{1}$ & $60{ }^{\circ} \mathrm{C}$ \\
\hline Primary Fixative & 10s On, 20s Off, 10s On & 650 & On & $60{ }^{\circ} \mathrm{C}$ \\
\hline Buffer Rinse & 1 Min & 150 & Cycle & $60^{\circ} \mathrm{C}$ \\
\hline Osmium Tetroxide $1 \%$ & 5 Min On, 2 Min Off, 5 Min On, 2 Min Off, 5 Min On & 200 & Cycle & $60{ }^{\circ} \mathrm{C}$ \\
\hline Buffer Rinse & $1 \mathrm{Min}$ & 150 & Cycle & $60{ }^{\circ} \mathrm{C}$ \\
\hline Uranyl Acetate $4 \%$ & 2 Min On, 2 Min Off, 2 Min On & 150 & Cycle & $60{ }^{\circ} \mathrm{C}$ \\
\hline Ethanol $25 \%, 1 \%$ Z-6040 & 5 Min & 250 & Cycle & $60{ }^{\circ} \mathrm{C}$ \\
\hline Ethanol $50 \%, 1 \%$ Z-6040 & 5 Min & 250 & Cycle & $60{ }^{\circ} \mathrm{C}$ \\
\hline Ethanol $75 \%, 1 \%$ Z-6040 & 5 Min & 250 & Cycle & $60^{\circ} \mathrm{C}$ \\
\hline Ethanol $85 \%, 1 \%$ Z-6040 & 5 Min & 250 & Cycle & $60^{\circ} \mathrm{C}$ \\
\hline Ethanol $95 \%$ & $5 \mathrm{Min}$ & 250 & Cycle & $60^{\circ} \mathrm{C}$ \\
\hline Ethanol $100 \%(x 3)$ & $5 \operatorname{Min}(x 3)$ & 250 & Cycle & $60^{\circ} \mathrm{C}$ \\
\hline Propylene Oxide $100 \%$ (x2) & $5 \operatorname{Min}(x 2)$ & 250 & Off & $60^{\circ} \mathrm{C}$ \\
\hline LX-112 Epoxy Resin $25 \%$ & $20 \mathrm{Min}$ & 250 & Cycle & $60^{\circ} \mathrm{C}$ \\
\hline LX-112 Epoxy Resin $50 \%$ & $20 \mathrm{Min}$ & 250 & Cycle & $60^{\circ} \mathrm{C}$ \\
\hline LX-112 Epoxy Resin 75\% & $20 \mathrm{Min}$ & 250 & On & $60^{\circ} \mathrm{C}$ \\
\hline LX-112 Epoxy Resin $100 \%(x 4)$ & $20 \operatorname{Min}(x 4)$ & 250 & On & $60^{\circ} \mathrm{C}$ \\
\hline LX-112 Epoxy Resin 100\% ${ }^{2}$ & $30 \mathrm{Min}$ & 250 & Off & $60^{\circ} \mathrm{C}$ \\
\hline LX-112 Epoxy Resin $100 \%$ & $90 \mathrm{Min}$ & 450 & Off & $100^{\circ} \mathrm{C}$ \\
\hline
\end{tabular}

Table 1. Optimized rapid microwave TEM protocol for botanical tissue. ${ }^{1}$ Vacuum cycles on and off every 30 seconds at 20 inHg. ${ }^{2}$ Polymerization in sealed beem capsules underwater.
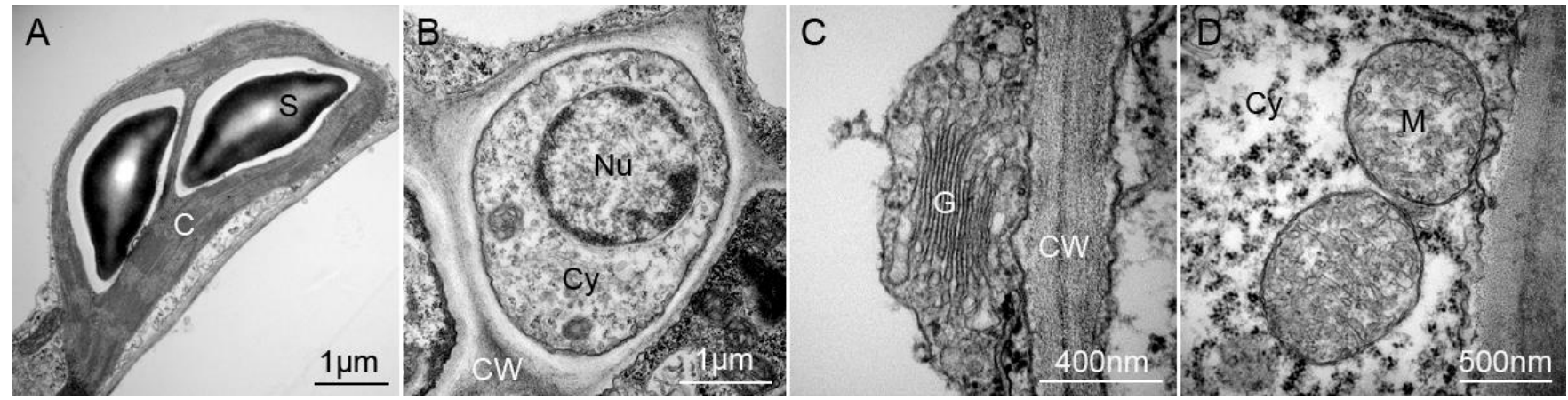

Figure 1. Ultrastructure of microwave processed tomato and tobacco leaves. (A) Tomato chlorophyll. (B) Tomato nucleus. (C) Tobacco Golgi body. (D) Tobacco mitochondria. $\mathrm{CW}=$ Cell wall; $\mathrm{C}=$ Chloroplast; $\mathrm{Cy}=$ Cytoplasm; $\mathrm{G}=$ Golgi body; $\mathrm{M}=$ Mitochondria; $\mathrm{Nu}=$ Nucleus; $\mathrm{S}=$ Starch. 